These are minor criticisms of the work and the authors are to be congratulated on epitomizing the new knowledge so successfully. No reader could fail to find in it information with which he was unfamiliar. Though there are three authors, the text is written throughout in a most readable style and the production is attractive. Everyone interested in tropical medicine should have this volume for reference purposes and for its valuable bibliography.

\section{Clinical Electroencephalography}

L. G. KILOH, M.D., B.SC., M.R.C.P., D.P.M., and J. W. Osselton, B.sc. Pp. ix + 135, illustrated. London: Butterworth. I96I. 50s.

It is a matter for regret that neurologists, unlike cardiologists, have neglected to take advantage of the diagnostic help which may be given by the electrophysiological methods applicable to clinical practice. This omission has resulted in these methods either being ignored or even derided, or being asked to provide answers beyond their competence. For those clinicians who wish to repair this defect, the present book provides an excellent opportunity.

It is reasonably short, a large part of the 135 pages being occupied by illustrative recordings. These are well situated with regard to the relevant text, and they clearly show what they are intended to demonstrate. The text is likewise concise and clear. Throughout the emphasis is on the clinical aspects of the subject. Technical explanations are kept to a minimum, but those without prior knowledge of the subject will have no difficulty in grasping the essential principles involved. There is also a considerable list of references for those who wish to pursue any aspect of the subject further.

The subjects covered, epilepsy, tumours, trauma, infections and degenerative conditions, are those seen in every-day clinical practice. The chapter on electroencephalography in psychiatry, while stressing the severe limitations of the method in this field, presents a clear picture of the present position.

The clinician, desirous of increasing his diagnostic skill, will find this book a reliable and easy guide.

\section{Essential Urology}

Fletcher H. Colby, M.D. Fourth edition. Pp. 603, illustrated. Baltimore: The Williams and Wilkins Co. London: Baillière, Tindall and Cox. r 961 . 64s.

This textbook opens with a thoroughly readable account of the embryology, anatomy and physiology of the genito-urinary tract. There is a conventional account of the methods of examination and the diseases of the genito-urinary tract are then described on an anatomical basis.

In assessing the value of a textbook for the undergraduate or postgraduate student one must turn to its account of certain subjects upon which opinions differ, or indeed in which much remains yet to be learnt, to see how clearly the student is led through these difficulties. It is a little disappointing to find chronic pyelonephritis described in the usual way as the late outcome of acute attacks of bacterial infection, and this despite the quotation of a reference that in $22 \%$ of one series no organisms could be identified in the urine.

There is an excellent and comprehensive discussion of urinary calculi, and one can suggest only that a rather more complete programme might be laid down for the investigations of such cases, whilst under the heading of treatment the valuable role of partial nephrectomy deserves further attention.
One of the commonest problems in general practice is that of the management of cases of benign hypertrophy of the prostate. This condition is quite fully considered, especially from the viewpoint of pathology. It is perhaps a little misleading to say that it is generally agreed that the process of benign hypertrophy is neoplastic, and the reviewer has personally never been satisfied with the statement here repeated that the "normal prostatic tissue is compressed into a thin rim by the continued enlargement of the tumour mass'. In the investigation of the condition cystography by air and the injection of radio-opaque media is described as an important method of gaining information on the size of the prostate and the degree of its obstruction. Teaching in this country would, on the whole, be very much against such a method with its dangers of introducing infection.

The management of acute retention is not adequately described and the problems in severe cases of renal failure from chronic retention, particularly that of the associated anæmia, warrant fuller treatment.

An important omission in this book is the management of anuria, with which the urologist of today must be familiar, as he may well find himself the surgical member of a hæmodialysis team.

This textbook may be described as quite a useful reference book written in a systematic manner. It must be admitted, however, that it is not sufficiently complete for the postgraduate student of urology, whilst for the undergraduate it is perhaps too detailed without giving really full guidance of those aspects of urology which are of everyday importance in general practice, particularly recurrent urinary infection, the management of acute and chronic retention in the male, and stress incontinence in the female.

\section{Cancer Chemotherapy}

By the staff of the University of Texas, M. D. Anderson Hospital and Tumor Institute, Texas Medical Center, Houston, Texas. Edited by R. Lee Clark, JR., M.D., D.SC.(hON.). Pp. xii + 253 , illustrated. Springfield, Illinois: Charles C Thomas. Oxford: Blackwells. i96 I. 84s.

This volume contains 14 articles, almost all by members of the staff of the M. D. Anderson Hospital and Tumor Institute, Texas Medical Center, Houston, Texas. There are two articles on the chemistry and basic biochemistry of substances already in clinical use and of potential chemotherapeutic agents. One contribution is devoted to a description of the national chemotherapy programme for the screening and testing of compounds destined for clinical trial. The remainder all deal with the clinical applications of chemotherapy throughout the whole field of human malignant disease. Malignant lymphoma, leukæmia and multiple myeloma are competently dealt with, the contributions of $D$. E. Bergsagel deserving special mention. The special problems of childhood malignancy are treated separately in malignant lymphoma and in 'solid tumours'. There are chapters on mammary carcinoma, on the prostate, thyroid and adrenal glands, and finally J. S. Stehlin writes on the surgical applications of chemotherapeutic agents.

There is a real need for a book entirely devoted to cancer chemotherapy, for it is becoming increasingly difficult for clinicians to keep up with the flood of literature and to know which, if any, of the newer substances are likely to be of help in treating their patients. To some extent this book will fill this need. It is useful to have under one cover the names and chemical formulæ of almost all the agents that have been claimed to be of 